\title{
Ground-penetrating radar for anthropological research
}

\author{
Lawrence B. Conyers*
}

During its development years, geophysical survey has served field archaeology by defining possible sites underground, prior to excavation or preservation. Now we can see the art taking off as a research method in its own right. After summarising some recent research applications of magnetic mapping, the author gives us three case studies from USA and Jordan, where ground-penetrating radar (GPR) has produced new interpretations of prehistory and history. Since GPR can map in horizontal slices without damage, it opens up important heritage preservation options. In one case, excavation was discouraged on ethical grounds, in another it was inhibited by the presence of later monuments and in a third, an early agricultural site, the GPR actually saw more than the excavators. This presages a research tool of particular power.

Keywords: Chaco Canyon, Las Capas, Petra, geophysical survey, magnetometry, radar, GPR, project design, evaluation, kivas

\section{Introduction}

Geophysical archaeology consists of a number of near-surface imaging methods used to produce maps and profiles of buried cultural remains and associated stratigraphy, usually within a few metres of the surface. Various techniques have been commonly employed to accommodate varying ground conditions, the types of remains that might be encountered, the amount of area to be surveyed, the depth of burial and the resolution necessary (Gaffney \& Gater 2003). Many of the methods generally employed by the archaeological community were modified directly from other disciplines, where the focus was usually on geotechnical and environmental uses and the search for hydrocarbons and other minerals. As a result, the early practitioners of geophysical archaeology originated not in the archaeology or anthropology fields, but were often recruited from physics, geology or other scientifically-based disciplines (Bevan 1983; Weymouth 1986; Clark 1990; Scollar et al. 1990). The perceived usefulness of the methods within the archaeology community was often based on an ability to find interesting buried materials that could later be excavated using standard archaeological techniques. In the early days of geophysical archaeology, this 'prospection' was often followed by excavation designed to expose features and analyse artefacts in order to interpret aspects of the human past.

* Department of Anthropology, University of Denver, 2000 E. Asbury St., Denver, CO 80208, USA (Email: lconyers@du.edu)

Received: 8 May 2009; Accepted: 7 July 2009; Revised: 10 July 2009

ANTIQUITY 84 (2010): 175-184

http://antiquity.ac.uk/ant/84/ant840175.htm 
This historical application of geophysical archaeology as purely an exploratory tool is still quite prevalent in the minds of many archaeologists, the goal being to search for buried cultural materials for subsequent excavation, or sometimes for their preservation by avoiding development damage. However, a small but growing community of geophysical archaeologists has lately begun to use powerful geophysical imaging techniques for more than mere prospecting, and to incorporate them into their research projects in much more holistic ways. These researchers use geophysical methods (often accompanied by, and integrated with, standard excavation procedures) as a way to ask questions and test anthropological and historical hypotheses about the human past, by relating site layout, feature size and orientation and other aspects of cultural remains to various human behaviours. In this way archaeological geophysical results are beginning to become a primary data source from which to study the human past, not merely a preliminary to standard excavation procedures (Kvamme 2003). This enlarged use of geophysics has recently been made possible by advances in data collection and processing, both of which are the product of more powerful computers and the development of intuitive software.

Four techniques are widely used by the archaeological community: magnetics, electrical resistivity, electromagnetic induction (EM) and ground-penetrating radar (GPR) (Gaffney \& Gater 2003; Campana \& Piro 2009). Each of these techniques has been refined to the point where data can be rapidly collected and processing can be accomplished almost immediately on a laptop computer. Maps and images of the ground that are produced often lead directly to interpretation.

\section{Geophysics for understanding the past}

Magnetic gradiometry, calibrated with augers, cores and limited subsurface excavations, was used to identify prehistoric house features, storage pits and other features in South Dakota, USA (Kvamme 2003). While producing impressive large-scale maps of an ancient fortified village, the clarity of houses and associated cultural features in the maps allowed for an estimation of the village population and the number and volume of storage pits for agricultural products. From those data the potential food storage and distribution could be estimated to arrive at subsistence estimates per household. Episodes of burning were also identified in some areas and a contraction of the village within defensive walls over time showed evidence of warfare and subsistence stress. The usage of space within the defensive walls also delineated areas where people of different status probably resided and helped to define periods of cultural upheaval and stress (perhaps brought about in part by climatic change) on the American Great Plains.

In a similar fashion Gaffney et al. (2000) also used magnetic maps to produce images of the ancient Roman city of Wroxeter, England. In their analysis, certain aspects of the geophysical signature were used to identify historic use areas, streets, neighbourhood plans and areas of industrial activities. The results could also discriminate high and lower status habitation areas based on a spatial analysis of certain magnetic signatures. The results tested, and refuted, a prevalent hypothesis that the city consisted of open spaces and 'gardens' within town walls. Wroxeter was found to be a well-developed city with industrial and residential neighbourhoods for people of various status, within defensive walls. 
A similar analysis was done in Syria, where extensive magnetic maps of a RomanoHellenistic city were used to differentiate various neighbourhoods and districts (Benech 2007). That study identified functional aspects of certain domestic dwellings, such as size of reception rooms, courtyards and number of associated habitation rooms. The results were analysed statistically and hypotheses were tested regarding the possible ancient use of some households. Conclusions indicate that some areas of the city were reserved for religious or administrative functions, while other areas were for more general habitation.

These magnetometer studies were capable of producing images of many hectares relatively efficiently, as data could be collected in closely spaced transects within grids at a rate as fast as a person could walk. While the magnetometer method is one of the most efficient methods at covering a great deal of ground quickly, one drawback is its inability to discriminate accurately between vertical layers; it tends to average readings over an approximate resolution depth (Aspinall et al. 2008). It is a technique suitable for relatively shallow archaeological features distributed over large areas where the geological matrix is fairly uniform and there is little associated stratigraphic complexity. This is also the case for the EM and resistivity methods, although all three have some basic abilities to discriminate general depths (Gaffney \& Gater 2003).

In contrast, GPR has the unique ability to gather data from known depths and produce images of specific layers or horizons. This is because it transmits radar pulses into the ground and records the elapsed time from when they are sent, reflected from buried materials, and received back at the surface (Conyers 2004). That elapsed time can then be converted to depth, and specific depth levels in the ground can be mapped individually, producing threedimensional layered images and maps of cultural materials. The trade-off is that GPR data are slower to collect, and therefore the method is only rarely used to map extensive sites (a notable exception is Neubauer et al. 2002).

Here I discuss three case studies in which GPR was used not solely to locate buried cultural remains, but to apply the resulting images and maps, integrated with standard subsurface testing, directly to test hypotheses about human behaviour.

\section{Comb Wash, Utah}

In the American Southwest cultural connections between widely spaced communities in the high desert of the Colorado Plateau have been studied for decades (Cordell 1997). About AD 900 a central place, in what is now called Chaco Canyon, New Mexico, was indisputably the most important ceremonial and perhaps economic and political centre of the region (Cordell 1997; Lekson 2006). Roads across large expanses of desert led for hundreds of kilometres directly to Chaco Canyon, which contained large and architecturally impressive 'great houses' and 'great kivas'. Great kivas were semi-subterranean circular structures as much as $20 \mathrm{~m}$ in diameter, which appear to have been used for large communal ceremonies. Long distance trade that took place with people far to the south in present day Mexico and elsewhere has been documented, illustrating Chaco's prehistoric far-reaching connections. Many hundreds of kilometres away from the Chaco 'centre', people built structures that were smaller, but still appear to have architecturally emulated those at the centre of this influential 
Ground-penetrating radar for anthropological research
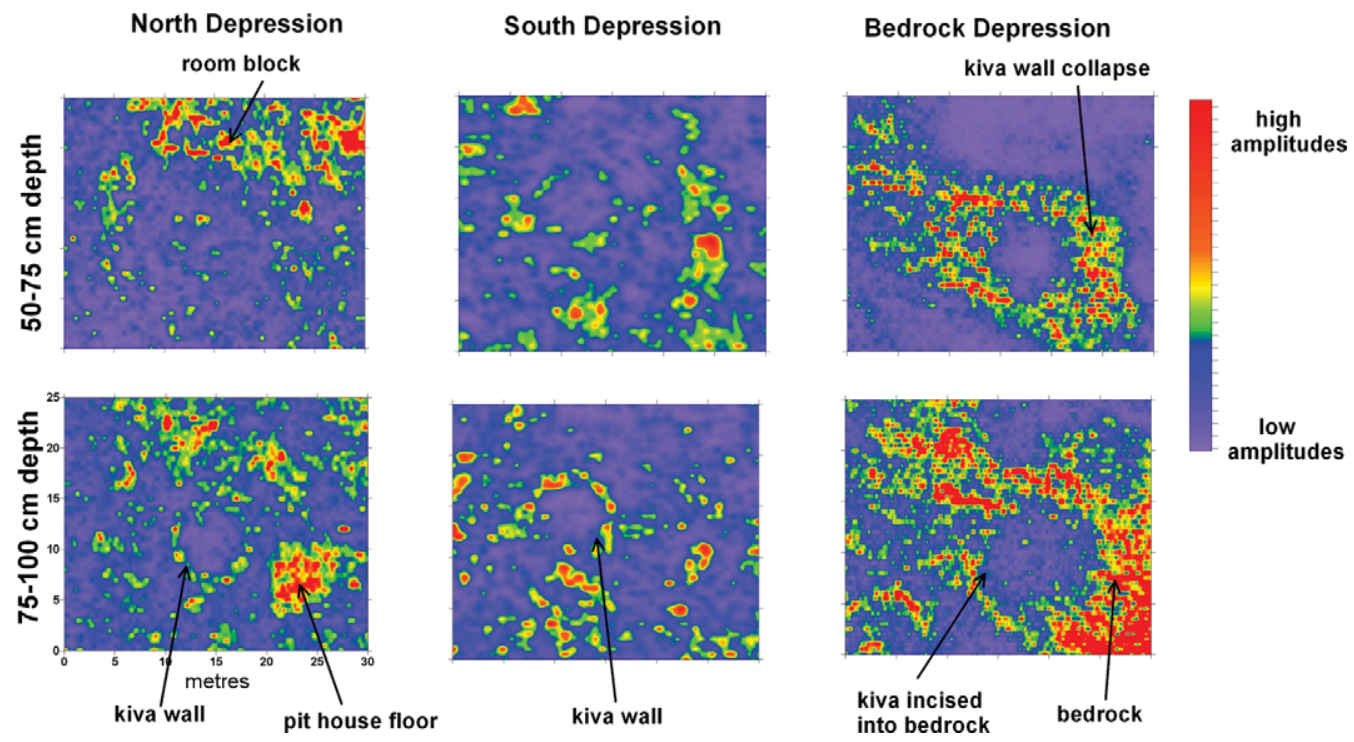

Figure 1. GPR amplitude slice-maps from Comb Wash, Utah. A shallow room block and deeper pit house and kiva are visible within the north depression. In the south depression one kiva is visible, while in the bedrock depression a kiva, partially collapsed, can be seen incised into the bedrock. Refection amplitude colours are relative after range gains were applied to the collected amplitudes.

prehistoric 'system'. While the inhabitants of these peripheral communities were definitely influenced in some way by Chaco, and might have even travelled there for important rituals or other reasons, the nature of these interactions and connections are still being debated (Lekson 2006).

One area on the north-west periphery of the Chaco sphere of influence is located in Comb Wash, Utah, about $250 \mathrm{~km}$ from the central core. Great houses have been found nearby, which are much smaller and less impressive than those in Chaco Canyon proper but still built in a Chaco-style. Nearby are a number of large circular depressions whose diameters are equal in size to the intensively studied great kivas at Chaco Canyon. Prior to GPR analysis these large circular depressions were assumed to be great kivas and their presence used to hypothesise that they played a similar role to those in the Chaco centre (Hurst 2000). An additional hypothesis was that the buried structures had perhaps been looted or robbed for stone in the past, enlarging the surface depression, but their perfect circular surface expression tended to refute this idea. Excavation of these circular features had not occurred as they are located on US Government managed lands, and also because of sensitivity for the descendant communities living in the area.

To test the hypothesis that such a concentration of apparent great kivas at Comb Wash was evidence of a Chaco-like regional centre, GPR surveys were conducted on five of the large diameter circular depressions (Conyers \& Osburn 2006). Many hundreds of GPR profiles were collected in grids over each depression using $400 \mathrm{MHz}$ antennas, yielding a subsurface resolution of about $20 \mathrm{~cm}$ at depths of up to $2 \mathrm{~m}$ (Conyers 2004). The amplitudes 
of reflected waves, which are a function of compositional differences in buried materials in the ground, were then gridded and mapped in $25 \mathrm{~cm}$ thick horizontal slices, analogous to standard archaeological excavation levels. When this was done the circular walls of kivas were apparent (Figure 1). However, only three of the five large depressions contained kivas and those were found to be small domestic-size kivas no larger than about $5 \mathrm{~m}$ in diameter. Also, the GPR images showed that associated with one of the kivas was an above-ground room block and evidence of other earlier features such as pit houses and storage cisterns. The two large depressions where GPR showed no buried architecture are likely to be the remains of historic water reservoirs from cattle ranching operations.

The GPR maps at three sites illustrate small domestic kivas consistent with long-term, relatively modest farming communities. Limited excavations and coring were undertaken at one of these sites, confirming the GPR results and yielding pottery dates coincident with the Chaco period of influence. The results of this study have necessitated a re-thinking of the prehistory of the Comb Wash area within the greater Chaco interaction sphere. Instead of this area being a regional ceremonial or other Chaco-inspired centre of activity, it now appears to have been only peripherally influenced by Chaco. The GPR interpretation instead shows that prehistoric people at Comb Wash likely lived in this area for generations, renovating existing pit dwellings, building new kivas, storage facilities and above-ground room blocks, while practising every day farming activities. In this area GPR was ideal for producing maps of the complex three-dimensional aspects of the sites with superimposed architecture, which was sometimes associated with bedrock and other stratigraphic layers making other geophysical methods impossible.

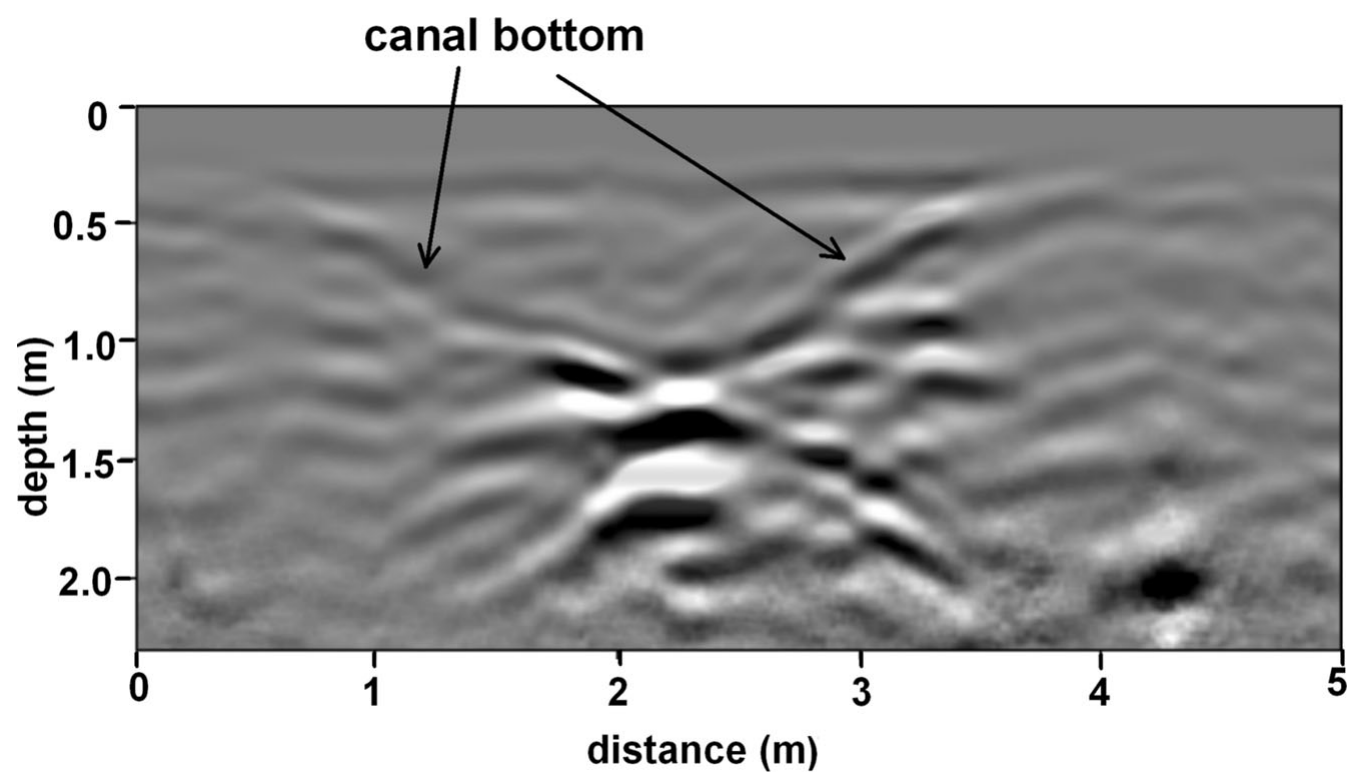

Figure 2. GPR reflection profile of an irrigation canal leading to large-scale Archaic age fields in the Santa Cruz River floodplain, Arizona. 


\section{Las Capas, Arizona}

Elsewhere in the American Southwest, during a much earlier time, recent excavations have exposed some of the earliest evidence for agricultural intensification in North America (Diehl 2005; Roth \& Freeman 2008). At a site called Las Capas, in the floodplain of the Santa Cruz River near Tucson, Arizona, irrigation canals and associated planting beds bounded by small earthen dykes have been discovered dating to about $2200 \mathrm{BC}$. These agricultural features are preserved under about $2 \mathrm{~m}$ of floodplain sand and silt. Geological studies suggest that the agricultural fields and water canals that fed them were periodically flooded and partially destroyed, necessitating constant cleaning and modification in order to exploit this productive environment for maize production.

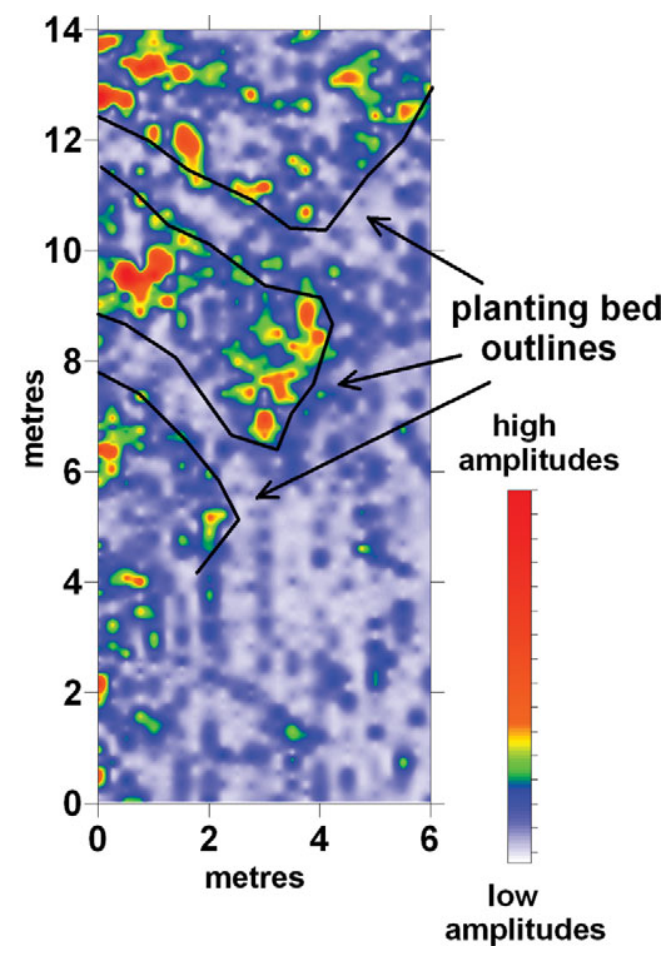

Figure 3. Subtle digging features and planting beds are visible as high amplitude reflections within one floodplain layer containing Archaic fields, Santa Cruz River, Arizona. Reflection amplitude colours are relative.
As a test of the GPR method's ability to map very subtle silt and clay features within the floodplain sediment package, GPR reflection profiles were collected in a number of areas slated for excavation. When the GPR reflection amplitudes were mapped in both profile and in plan view along specific horizons, subtle features such as irrigation canals and planting beds became visible. When they were excavated and studied visually, only a trained geologic eye could identify these subtle features. In GPR reflection profiles the subtle canals consisting of fine-grained sand and silt within a similar sedimentary matrix were visible in profile (Figure 2). The images were clear enough to see periodic flooddeposited silt beds within the channels, which ultimately led to their abandonment after about a century or less of use-life (Fred Nials, pers. comm.). The planting beds, produced by these ancient farmers by digging out clay along shallow ditches and using it for small dykes to impound in the waters from the distribution canals, could also be mapped with GPR, demonstrating the extensive nature of this early agricultural intensification (Figure 3). This geophysical information, and data obtained from standard excavations, demonstrates that these Archaic age people were long term residents of the area who intensively utilised the floodplain environment for agricultural production that probably represented a good part of their diet. It now appears that this area of the Sonoran Desert was a focal area for agricultural experimentation very early in the history of semi-sedentary occupation, from which agricultural techniques and products dispersed outward through the western portion of 


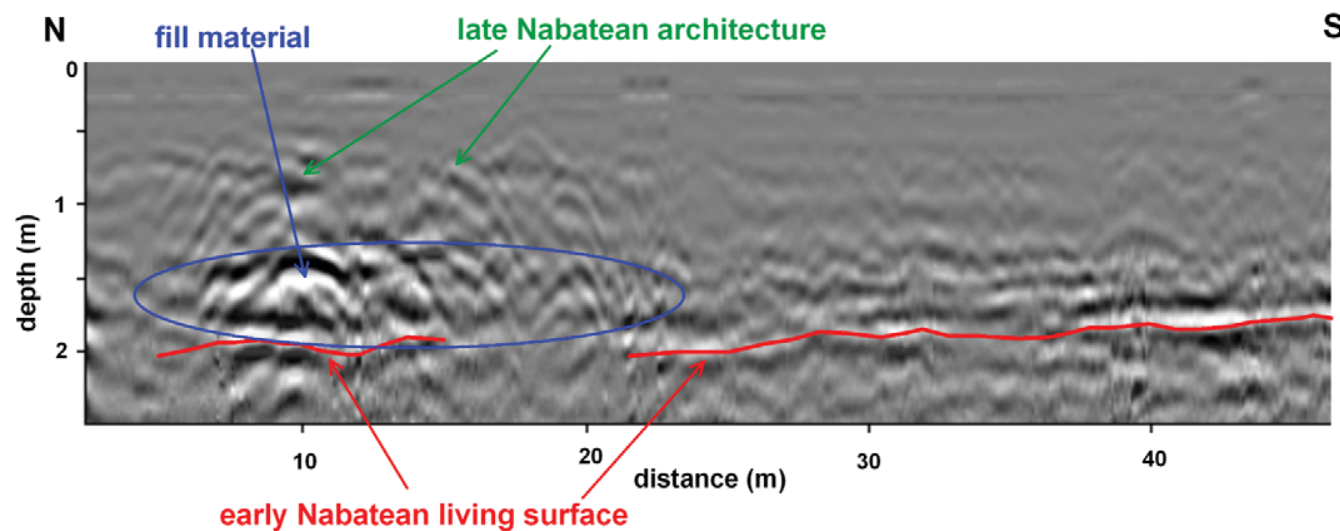

Figure 4. GPR reflection profile showing stratigraphy at the Lower Market, Petra. The discontinuous and complex early Nabataean living surface is overlain by fill material, upon which was built late Nabataean monumental buildings.

the US over many centuries. In this project, GPR's ability to define and then produce images of a small slice within a complex stratigraphic sequence allowed these subtle features to become visible. Data-processing methods that produced images of these very subtle features, often not readily visible to the human eye even when exposed, proved to be a key to understanding this complex and deeply buried archaeology within a complexly layered floodplain environment.

\section{Petra, Jordan}

At the site of Petra in Jordan, much is known about the late Nabataean and Roman occupation of this impressive desert valley (Schmidt 2001). While formal Roman annexation did not occur until AD 106, monumental construction with Hellenistic influences began about a century earlier, perhaps as early as the mid to late first century BC by the Nabataeans who had become wealthy by controlling trade routes in the area. There is also subtle and potentially important evidence of earlier Nabataean occupation of the valley from the second and early first centuries BC by people who originally lived in much more humble dwellings (Parr 1970). These structures were probably razed and covered over during a first-century urbanisation campaign, which created a city layout that can be seen at or near the surface of Petra today (Schmidt 2001). Some interesting questions that have been posed, but never adequately tested, relate to the social structure and community planning of the earliest Nabataean settlements, as much of the archaeological evidence of these earliest inhabitants was either destroyed or buried during the city renovation (Hammond 1991).

One site at Petra, which allowed for the production of maps of the early Nabataean structures, is the Lower Market, just east of the Great Temple (Conyers et al. 2002; Bedal 2003). This open area had seen little archaeological work prior to Bedal's excavations, and almost no deep testing of the earliest horizons, other than a tantalising trench excavated into it from the Colonnaded Street, just to the north, by Parr (1970). In that trench the possible foundations of early Nabataean dwellings were exposed, and dated by pottery. The stratigraphy in that trench also demonstrated that an ancient living surface from earliest 
Nabataean times was covered by a large amount of fill during the urban construction in the late first century BC.

In order to test the presence of possible preserved architecture below the present ground surface, one large grid of GPR reflection profiles was collected (Conyers et al. 2002). Images of the shallowest buried architecture, within about $2 \mathrm{~m}$ of the surface, showed a number of temples, platforms, water lines and possible water pools consistent with Bedal's (2003) interpretation of this area as a formal garden.

As GPR reflection data that are collected in a grid produce a three-dimensional block of information about the subsurface, early Nabataean features below the late first-century BC fill can also be mapped (Figure 4). Reflection profiles within the grid show a very subtle sloping reflection correlative to an ancient living surface. It was hypothesised that this represents the topography of the valley prior to the first-century urbanisation construction episode, which covered it and levelled the surface of the Lower Market. On that reflection surface visible in the GPR profiles can be seen other subtle features that were generated from preserved architecture and architectural rubble on that living surface. Velocity analysis to convert radar travel times to depth, and a correlation of GPR reflections to the depths of features exposed in the trench to the north, indicated that this reflection was probably produced from a horizon of early Nabataean age.

In order to produce images of that buried surface, the amplitudes of all GPR reflections in all profiles within the grid were digitised, gridded and mapped in slices parallel to the sloping ancient living surface (Figure 5). The highest amplitude reflections correspond to either standing architecture or architectural rubble on and directly above this buried surface. Areas with no significant reflection are probably open spaces or pathways between buildings on that early Nabataean living surface. This type of GPR analysis produces horizon-specific maps showing the remains of simple buildings (Grealy 2006) and possible pathways between them. The pathways are identifiable as linear zones of no reflection, which led from the highlands to the south, toward the water drainage to the north (Figure 5B and C). The orientations of the early Nabataean informal buildings along these pathways show that they were built in various orientations and probably placed on land that was suitable for building at that time. This type of informal construction probably functioned only as part-time living quarters by people still involved in long-distance trade (Schmidt 2001). Only later in the late first century BC, when the Nabataeans had established control over trade routes from south Arabia to the eastern Mediterranean, did social differentiation and monumental construction take place. The remains of these later more formal buildings (Figure 5A) from that construction period are in stark contrast to these earliest habitations. In the upper GPR slice the structures within what became a formal garden were invariably oriented to the cardinal directions, consistent with Hellenistic influenced building practices from later Nabataean times.

In this study, the architecture from two different periods within one small area of Petra demonstrates the very different types of city planning and social structure held by the inhabitants of Petra over three to four centuries. The GPR analysis of two distinct layers of the Lower Market demonstrate that the earliest Nabataean inhabitants built their structures along functional pathways leading to water, which is very much a reflection of their history as semi-nomadic people. In contrast, the upper GPR map shows that, as the 

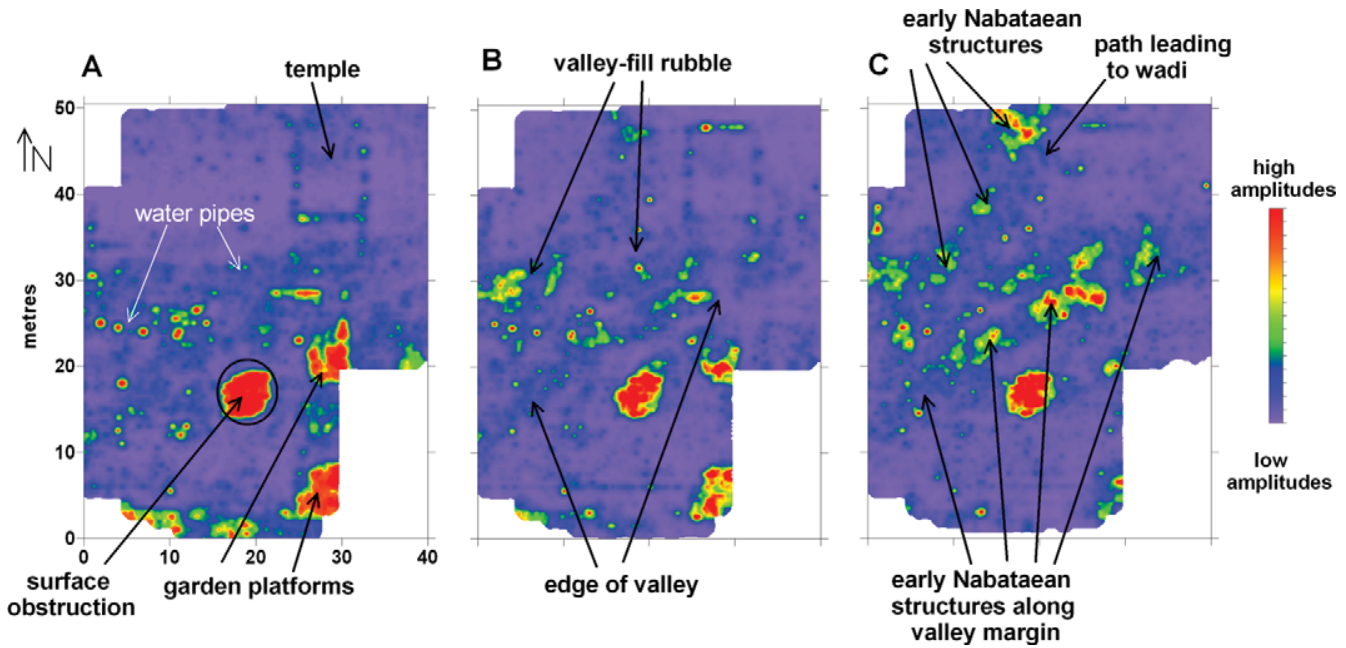

Figure 5. GPR amplitude slices from the Lower Market, Petra, latest on the left, earliest on the right. Slice A is from the $75-100 \mathrm{~cm}$ depth, which shows late Nabataean and Roman period structures built when the area was a formal garden. Slice $B$ shows rubble fill and the valley edge in a $25 \mathrm{~cm}$-thick slice directly above the horizon that was an earlier Nabataean living surface, occupied prior to the late first century $B C$ urbanisation program. Slice $C$ is a $25 \mathrm{~cm}$-slice directly on that earlier living surface showing the foundations and remains of Nabataean structures built along the sides of the valley, with a pathway leading to the water course to the north. Reflection amplitude colours are relative.

city grew and prospered beginning in the first century BC, the built environment followed a more strict conformation with what suggests central planning and a much stricter and perhaps economically and politically differentiated social structure. The GPR images, when correlated to limited excavation information, produced images of these two buried landscapes and the structures built on them, in ways not possible with any other archaeological method except perhaps by massive excavations.

\section{Conclusion}

Geophysical methods in archaeological research have progressed to the point that they can be used as much more than exploratory tools. While the resulting maps and other images must still be integrated with chronological and artefact information from excavation so that they may be placed within a cultural history, they can often be used directly to test ideas about the past. Social change, technological innovations and ecological adaptations can potentially be studied based on the orientation, layout and change of buried features that are visible using GPR data. Ground-penetrating radar is a geophysical method especially effective in some deeply buried or stratigraphically complex environments because of the method's ability to discriminate important layers and map only certain levels or horizons. This type of complex stratigraphic analysis is usually impossible using other geophysical techniques. When GPR results are integrated with other data from standard archaeological methods it fits nicely into the quantitative and scientific approach of studying many aspects of ancient life. When hypotheses about ancient people can be related directly to the extent, orientation or geometry of buried architecture and associated anthropogenic features, geophysics can be used to directly support or refute hypotheses about the human past. In the future, 
archaeologists can potentially produce models about past behaviour, and then test these concepts directly using a combination of three-dimensional GPR mapping and standard excavation techniques.

\section{Acknowledgements}

Many thanks are due to Leigh-Ann Bedal, Cathy Cameron, Jim Vint and Fred Nials for logistical field support. Dumbarton Oaks, Desert Archaeology and SERDP were crucial in financial support of these projects and Tiffany Osburn and Michael Grealy for GPR data collection and processing.

\section{References}

Aspinall, A., C. GAFFney \& A. SCHMidT. 2008. Magnetrometry for archaeologists. Walnut Creek (CA): Alta Mira.

Bedal, L.-A. 2003. The Petra Pool-Complex: a Hellenistic paradeisos in the Nabataean capital (results from the Petra 'lower market' survey and excavation, 1998) (Gorgias Dissertations 5; Near Eastern Studies 5). Piscataway (NJ): Gorgias.

BENECH, C. 2007. New approach to the study of city planning and domestic dwellings in the ancient Near East. Archaeological Prospection 14: 87-103.

BEVAN, B.W. 1983. Electromagnetics for mapping earth features. Journal of Field Archaeology 10: 47-54.

Campana, S. \& S. Piro. 2009. Seeing the unseen: geophysics and landscape archaeology. Leiden: CRE Press/Balkema.

Clark, A. 1990. Seeing beneath the soil: prospection methods in archaeology. London: B.T. Batsford Ltd.

CONYERS, L.B. 2004. Ground-penetrating radar for archaeology. Walnut Creek (CA): Alta Mira.

Conyers, L.B. \& T. Osburn. 2006. GPR mapping to test anthropological hypotheses: a study from Comb Wash, Utah, American Southwest, in J.J. Daniels \& C.-C. Chen (ed.) Proceedings of the 11th International Conference on Ground Penetrating Radar, June 19-22: 200-205. Columbus (OH): Ohio State University.

Conyers, L.B., E.G. ERnenwein \& L.-A. Bedal. 2002. Ground-penetrating radar discovery at Petra, Jordan. Antiquity 76: 339-40.

CORDELl, L. 1997. Archaeology of the Southwest. New York: Academic Press.

DIEHL, M.W. 2005. Subsistence and resource use strategies in early agricultural communities in southern Arizona (Anthropological Papers 34). Tucson (AZ): Center for Desert Archaeology.

GAFFNEY, C. \& J. GATER 2003. Revealing the buried past: geophysics for archaeologists. Stroud: Tempus.

Gaffney, C.F., J.A. Gater, P. Linford, V.L. Gaffney \& R. WHITE. 2000. Large-scale systematic fluxgate gradiometry at the Roman City of Wroxeter. Archaeological Prospection 7: 81-99.
GreALY, M. 2006. Resolution of ground-penetrating radar reflections at differing frequencies. Archaeological Prospection 13: 141-5.

Hammond, P. 1991. Nabataean settlement patterns inside Petra. Ancient History Bulletin 2: 36-46.

Hurst, W.B. 2000. Chaco outlier or backwoods pretender? A provincial great house at Edge of Cedars Ruin, Utah, in J. Kantner \& N.M. Mahoney (ed.) Great house communities across the Chacoan landscape (Anthropological Papers of the University of Arizona 64): 63-78. Tucson (AZ): University of Arizona Press.

Kvamme, K.L. 2003. Geophysical surveys as landscape archaeology. American Antiquity 68: 435-57.

LEKSON, S.H. 2006. The archaeology of Chaco Canyon: an eleventh century Pueblo regional center. Santa Fe (NM): School of Advanced Research Center.

Neubauer, W., A. Eden-Hinterleitner, S. Seren \& P. Melichar. 2002. Georadar in the Roman civil town Carnutum, Austria: an approach for archaeological interpretation of GPR data. Archaeological Prospection 9: 135-56.

PARR, P.J. 1970. A sequence of pottery from Petra, in James A. Sanders (ed.) Near Eastern archaeology in the twentieth century: essays in honor of Nelson Glueck: 348-81. Garden City (NJ): Doubleday.

Roth, B.J. \& A. FreEman 2008. The Middle Archaic Period and the transition to agriculture in the Sonoran Desert of southern Arizona. Kiva 73: 321-53.

SCHMIDT, S.G. 2001. The Nabataeans: travelers between lifestyles, in B. MacDonald, R. Adams \& P. Bienkowski (ed.) The archaeology of Jordan (Levantine Archaeology 1): 367-426. Sheffield: Sheffield Academic Press.

Scollar, I., A. Tabbaugh, A. Hesse \& I. Herzon. 1990. Archaeological prospecting and remote sensing. Cambridge: Cambridge University Press.

Weymouth, J. 1986. Geophysical methods of site surveying, in M.B. Schiffer (ed). Advances in archaeological method and theory: 311-95. New York: Academic Press. 